\title{
MOVIMIENTO DE REGENERACIÓN NACIONAL: DEMOCRACIA INTERNA Y TENDENCIAS OLIGÁRQUICAS
}

Rosendo Bolíivar Meza

\section{INTRODUCGIÓN}

El objetivo de este trabajo es analizar la democracia interna y las tendencias oligárquicas del partido Movimiento de Regeneración Nacional (Morena), el cual surge como asociación civil en 2011; obtiene su registro como partido político nacional en 2014; participa por primera vez en el proceso electoral federal de 2015.

Se parte de la premisa de que la democracia interna en un partido político consiste en que se cumplan los mecanismos institucionales que respeten su forma de organización y se actúe con base en sus propias normas y procedimientos. Se basa en el derecho de participación de los afiliados y el derecho de autoorganización de los partidos, normando su funcionamiento interno en reglas democráticas que se plasman en el reconocimiento de derechos y atribuciones propias de quienes se adhieren al proyecto partidista y se comprometen con él. ${ }^{1}$

Se expresa en la renovación periódica de sus cuadros directivos mediante procesos electivos, apegados a sus estatutos, sin que se generen conflictos, y en que se reconozcan los resultados sin ser cuestionados. Una vez electa la dirigencia de un partido, ésta debe mantener cercanía con las bases y tomar en cuenta sus opiniones.

${ }^{1}$ Adriana Gallo, "La democracia interna en el ámbito partidario. Un estudio comparado en partidos latinoamericanos”, Reflexión Política, vol. 7, núm. 14, 2005, pp. 29-30. 
También se manifiesta en la forma de selección de sus candidatos a puestos de elección respecto a la naturaleza de las candidaturas, en el caso de que los candidatos sean elegidos sólo entre los militantes o se abra esta opción a la ciudadanía; si surgen producto de una elección interna, un proceso de designación o por algún otro mecanismo aleatorio.

Hay al menos cuatro elementos que ayudan a identificar si un partido es democrático o no:

1) El respeto y la garantía de los derechos fundamentales en el partido. Se refiere a si la participación es directa o mediante representantes en las asambleas generales, a su periodicidad, a la responsabilidad y revocabilidad en los cargos y en los órganos directivos, al carácter colegiado de los órganos de decisión, a la vigencia del principio mayoritario en los órganos del partido y a la libertad de expresión en su interior.

2) La organización y los procedimientos internos. Consiste en que la voluntad se forme de abajo hacia arriba y nunca en sentido inverso. Por ello, la asamblea general es el órgano supremo de donde emanan las principales líneas doctrinarias y de acción de los partidos, como resultado de una decisión mayoritaria.

3) Las corrientes en el seno de la organización. Pese a sus críticas por ser posibles fuentes de división en los partidos, siempre es mejor tener varias concepciones que puedan generar consensos y disensos, que un inmovilismo político producto de una sola visión que impida la alternancia en su seno.

4) Los órganos de control de su vida interna. Éstos hacen factible el respeto y la garantía de los derechos humanos, así como la posibilidad de las sanciones para el caso de la violación a la estructura funcional y organizativa del partido. Se requiere que sean neutrales, capaces de conocer y resolver impugnaciones a las decisiones arbitrarias que pudieran tomar los órganos ejecutivos partidistas. ${ }^{2}$

La oligarquización en un partido político consiste en la apropiación de los puestos de dirección por grupos de interés en su interior. La lucha interna por el poder en cada partido en busca de

2 Jaime Cárdenas Gracia, Crisis de legitimidad y democracia interna de los partidos políticos, México, Fondo de Cultura Económica, 1992, pp. 209-242. 
su dirección produce fricciones y rupturas entre las corrientes que lo conforman, reduciendo su democracia interna y grado de institucionalización. ${ }^{3}$

Según Mauricio Duverger, ${ }^{4}$ la dirección de los partidos políticos presenta el doble carácter de una apariencia democrática y de una realidad oligárquica. Se esfuerza por conservar una apariencia democrática, en tanto que los procedimientos autoritarios y oligárquicos se desarrollan generalmente sin tener en cuenta los estatutos, ${ }^{5}$ por una serie de procedimientos desviados, pero eficaces, con lo que se establece un poder autocrático detrás de fórmulas y decorados democráticos.

Los dirigentes de los partidos políticos son elegidos periódicamente, casi siempre, por sus miembros, y son provistos de un mandato temporal, según las reglas democráticas. En muchos casos, el sistema democrático de elecciones se sustituye con técnicas de reclutamiento autocrático como cooptación o designación. Esto se ve agravado muchas veces por el hecho de que los jefes reales de los partidos a menudo son distintos que los jefes aparentes (o formales).

El sufragio indirecto para la renovación de la dirigencia de un partido consiste en que sus dirigentes no son elegidos por sus miembros, sino por delegados salidos de ellos mismos mediante una elección interna. No todos los partidos aplican el sufragio indirecto con el mismo rigor, pero todos lo utilizan. El sufragio indirecto es un medio admirable para prescindir de la democracia,

${ }^{3}$ Rosendo Bolívar Meza, "La oligarquización del Partido de la Revolución Democrática bajo la dirigencia de Nueva Izquierda", en Francisco Casanova Álvarez y Gabriel Corona Armenta (coords.), Democracia interna y tendencias oligárquicas de los partidos políticos en México: PAN, PRI y PRD, México, Facultad de Estudios Superiores Acatlán-UNAM-Gernika, 2013, pp. 229-273; véanse, particularmente, pp. 229-232.

${ }^{4}$ Mauricio Duverger, Los partidos políticos, México, Fondo de Cultura Económica, 1984, pp. 163-211.

${ }^{5}$ Los estatutos son el principio del análisis organizativo de los partidos. Es muy común que éstos sean modificados con la intención de conservar el poder de los dirigentes en funciones, quienes frecuentemente también son los propios fundadores de los partidos. Véase Ángelo Panebianco, Modelos de partido, México, Alianza Universidad, 1990, p. 87. 
fingiendo aplicarla. La elección de dirigentes de un partido por un pequeño grupo de delegados no tiene el mismo carácter que una elección directa realizada por todos sus afiliados. La elección indirecta tiene como efecto disimular una designación más o menos autocrática bajo una apariencia más o menos democrática.

Una de las expresiones más comunes de las tendencias a la oligarquización de un partido es la falta de renovación de sus cuadros dirigentes, con lo que se afecta su democracia interna. La dirección de los partidos tiende naturalmente a tomar una forma oligárquica. Se constituye una casta cerrada, un círculo interior de difícil acceso. En teoría la elección debería impedir el nacimiento de una oligarquía, pero parece, más bien, favorecerlo. Esto ocurre porque las masas, a menudo, son conservadoras, se apegan a sus viejos jefes y desconfían de los nuevos liderazgos.

El "círculo interior" de un partido tiene un enorme poder, porque suele ser el que selecciona a los candidatos para puestos de elección popular. En cambio, cuando las candidaturas son libres y abiertas a la ciudadanía, y el reclutamiento de los candidatos se hace fuera del círculo interior y de la oligarquía, el partido se abre a la circulación de las élites o ésta se hace posible.

Según Duverger, hay varios tipos de clases de jefes o de círculos interiores en un partido político. Pueden ser clanes constituidos alrededor de un líder influyente que reviste el carácter de una oligarquía en el partido (pueden ser las corrientes). Equipos y clanes constituyen oligarquías personales o de grupo, mientras que la burocracia es una oligarquía institucional. Cuando la dirección de un partido toma el carácter de una oligarquía, se plantean dos problemas en su interior: el de la composición del círculo interior y el de su renovación. El primero consiste en medir la separación entre la estructura social de la masa de miembros y la de los miembros del círculo interior o dirigencia. El otro se refiere a que toda oligarquía tiende a envejecer y, por tanto, debe darse la renovación de los cuadros dirigentes del partido, el rejuvenecimiento del círculo interior. El grado de envejecimiento de los cuadros y las posibilidades de renovación dependen grandemente de la organización misma del partido. La elección no asegura un rejuvenecimiento satisfactorio. 
La forma de autoridad se modifica en los partidos. En una primera fase, se pasa lentamente de una dirección personal a una dirección institucional y, en ocasiones, esto puede tender a la oligarquía. Los principales líderes acumulan mandatos electivos (cargos de elección popular o en la burocracia nacional) y puestos directivos en el partido. Para Robert Michels, ${ }^{6}$ los procesos electorales con los que periódicamente se renueva la dirigencia de un partido pueden propiciar, y, de hecho, han propiciado, el surgimiento de oligarquías, no tanto porque busquen perpetuarse en el cargo más de lo debido, como por las enormes posibilidades de maniobra que pueden practicar una vez que han obtenido el cargo, por lo que tienden a tomar una forma oligárquica, al convertirse la nueva dirigencia en un grupo compacto, con un círculo de integrantes prácticamente cerrado, independientemente de su forma de elección.

Las tendencias oligárquicas se refuerzan, porque quien posee autoridad y mando en un partido busca ampliarlo, fortalecerlo y extenderlo, pero, sobre todo, tiende a sustraerse de la tutela y el control de las masas o bases del partido, aunque hayan sido éstas quienes condujeron a sus dirigentes al cargo con su elección. Esto ocurre porque aparece en los líderes una tendencia a aislarse de las masas.

Las tendencias oligárquicas en los partidos políticos se reflejan en la transformación de los liderazgos en cuerpos burocráticos, en la centralización de la autoridad, en los cambios en la postura ideológica, en el distanciamiento entre los líderes y las bases del partido, o en la elección de nuevos líderes mediante la cooptación y sin la influencia de las bases, todo lo cual afecta la democracia interna de los partidos. La centralización, burocratización y cooptación en los partidos inciden negativamente en su vida interna y pueden hacer que los deseos, aspiraciones y decisiones de los dirigentes prevalezcan sobre los de la mayoría de los militantes. ${ }^{7}$

${ }^{6}$ Teoría y sociología críticas de los partidos políticos, Barcelona, Anagrama, 1980, pp. 244-248.

${ }^{7}$ Véase Juan J. Linz, Michels y su contribución a la sociología, México, Fondo de Cultura Económica, 1998, pp. 71-72 y 94-95. 
Una contribución más reciente al estudio de la vida interna de los partidos políticos es la de Ángelo Panebianco y su concepto de "coalición dominante". Para él, los partidos políticos se comportan como burocracias que distribuyen incentivos para la obtención de sus fines, lo que les ayuda a conformarse como una coalición dominante. Para Panebianco, la organización en un partido, su burocratización, es motivo de alianzas y conflictos entre los diversos actores que la integran. Además de desarrollar sus actividades, la organización partidista también garantiza, perpetúa y acrecienta el poder de quienes la controlan, es decir de las élites restringidas que dirigen al partido.

Las reglas de la competencia, las relaciones con el entorno, las comunicaciones internas, las reglas formales, el financiamiento y el reclutamiento de nuevos militantes, está bajo el control de los dirigentes de la organización partidista. De aquí la tendencia, común a todos los partidos, a la concentración del poder en grupos reducidos, en lo que se denomina como la oligarquía o el círculo interno. ${ }^{8}$ Cada partido político posee características políticas propias y practica la democracia interna o entra en un proceso de oligarquización a su manera. Los partidos poco democráticos en su interior tienen un efecto negativo en la confianza de los ciudadanos hacia ellos.

Hay dos tipos de estudios sobre la democracia interna y las tendencias oligárquicas en los partidos políticos: los jurídicos y los politológicos.

En el primer caso, los estudios jurídicos se realizan mediante la revisión de los documentos básicos de un partido político, particularmente de sus estatutos, que son los que rigen su vida interna, donde se puede detectar, al menos formalmente, si plantea o no la democracia interna. Trabajar sólo este aspecto implica el riesgo de no observar el proceder político actuante de los partidos y no ver más allá de sus normas estatutarias. En ellos se debe poner especial atención en si se plantea o no la participación de los afiliados en el

${ }^{8}$ Cf. Á. Panebianco, op. cit., pp. 16, 65, 88 y 90. Para él, la coalición dominante puede disgregarse ante lo que denomina como las élites minoritarias, cuando no está en condiciones de controlar las zonas de incertidumbre organizativa, pp. 91-92. 
proceso interno de toma de decisiones y elección de los cuerpos directivos y candidatos para puestos de elección; si se respetan los derechos fundamentales de los afiliados; si hay mecanismos de control de las bases hacia los dirigentes; si hay periodicidad en las elecciones y son de carácter libre; si se pueden construir fracciones o corrientes al interior del partido; si sus órganos se conforman de manera colegiada; si se adopta la regla de mayoría de votos para la toma de decisiones; si la asamblea general o su equivalente es el principal órgano de decisión, además de si se favorece la circulación y sustitución de sus dirigentes evitando su reelección indefinida, entre otros aspectos. Aquí se puede encontrar el deber ser de la democracia interna de un partido.

En el segundo caso, además de la revisión jurídica de la reglamentación interna de cada partido, en los estudios politológicos se toma en cuenta también la forma real en que se llevan a cabo los procesos de selección de dirigentes y candidatos a puestos de elección, que son referentes importantes para conocer la existencia o no de democracia interna en los partidos políticos, ya que los estatutos y documentos básicos pueden plantear aspectos democráticos en la forma, pero en la realidad práctica pueden ser antidemocráticos. Se debe considerar cómo se realiza la distribución del poder, quién elige a quién, cómo se le elige y dónde se le elige, es decir en qué instancias del partido. Es en este tipo de estudios donde se puede analizar el ser, la forma real en que se practica o no la democracia interna de un partido y si tiende al autoritarismo y a la oligarquización. $^{9}$

Todos los partidos políticos están conformados por élites que ejercen el poder político y el control de forma oligárquica, operando de manera vertical y centralizando la toma de decisiones, la conformación de las dirigencias, la designación de candidaturas, el manejo de los recursos económicos, el reclutamiento de sus militantes e incurriendo en la cooptación de los cuadros, que además dominan la vida interna de sus organizaciones y son capaces de imponer sus decisiones por encima de los intereses de los militantes.

${ }^{9}$ Alberto Espejel Espinoza, "El estado de la cuestión de la democracia interna”, en F. Casanova Álvarez y G. Corona Armenta (coords.), op. cit., pp. 31-67. 
Sin embargo, hay variaciones en el estilo, intensidad y diversidad de sus tendencias a la oligarquización, y hay también modificaciones de esas tendencias en los propios partidos en el transcurso del tiempo. ${ }^{10} \mathrm{Al}$ tomar como referente teórico lo anterior, en este trabajo se busca realizar un análisis sobre la democracia interna y las tendencias oligárquicas del partido Morena, sobre aspectos relacionados con su vida interna en lo referente a su composición de poder, a los mecanismos en la toma de decisiones y a las formas de selección de la dirigencia partidista y de los candidatos que ocuparán los cargos de elección popular.

En este trabajo, se pretende ver si es una realidad fatal que los partidos políticos sean necesariamente oligárquicos y si Morena está inmerso en ese proceso, pese a que al igual que todos los partidos políticos dicen tener y garantizar la democracia interna. Esto se hará de dos maneras. La primera, desde el punto de vista jurídico, analizando su vida interna por lo que Morena plantea para sí mismo en sus documentos básicos, como son declaración de principios, programa y estatutos, donde plantea los principios que lo rigen, las acciones que tomará para la consecución de sus fines y su organización interna. La segunda, con un enfoque politológico, analizando su proceder político real durante su proceso de creación y elección de sus primeras dos dirigencias nacionales tanto en 2013 como en 2015, y en la primera selección de cuadros a cargos de elección popular para el proceso electoral de 2015.

\section{MORENA: LA CONCEPCIÓN DE Sí MISMO A TRAVÉS DE SUS ESTATUTOS}

Como todo partido político mexicano, Morena elaboró sus documentos básicos, los cuales fueron aprobados por las autoridades electorales. En ellos, se plantean los principios que lo rigen, las acciones que tomará para la consecución de sus fines y su organización

${ }^{10}$ Para ahondar en estos detalles, véase F. Casanova Álvarez y Víctor Rosales García, "Oligarquía y tendencias oligárquicas de los partidos políticos mexicanos", en F. Casanova Álvarez y G. Corona Armenta (coords), op. cit., pp. 84-99. 
interna, lo cual se expone en su declaración de principios, programa y estatutos, cuyos revisión y análisis permite saber cómo se percibe a sí mismo y conocerlo formalmente, dejando para el siguiente espacio el análisis de su proceder político.

Cabe señalar que para los fines de este trabajo sólo se retomarán los estatutos, pues es en ellos donde un partido político describe formalmente su vida interna y estructura organizativa. En este caso, se retoman para su explicación los artículos de los estatutos de Morena que tienen que ver con su composición para conocer formalmente su nivel de democracia interna y si presenta o no tendencias oligárquicas. Consta de 71 artículos divididos en ocho capítulos, más tres artículos transitorios.

En el capítulo 1, denominado "Definiciones y principios", y que incluye los artículos 1, 2 y 3 , Morena se define como un partido político de hombres y mujeres libres de México que luchan por la transformación pacífica y democrática. Su objetivo es lograr un cambio verdadero que garantice a todos una vida digna con derechos plenos, se realice la justicia, se viva sin temor y no haya exclusiones ni privilegios. Concibe como un cambio verdadero el ejercicio auténtico de la democracia, decidir de manera libre, que la representación ciudadana se transforme en una actividad de servicio a la colectividad, pero, sobre todo, en hacer realidad el amor entre las familias, al prójimo, a la naturaleza y a la patria. Define a sus integrantes como "los protagonistas del cambio verdadero". La afiliación al partido es libre, individual, pacífica y voluntaria, sin que se permitan facciones, corrientes o grupos que vulneren la soberanía de la organización. Rechaza la subordinación o alianzas con representantes del régimen actual y de sus partidos.

El capítulo segundo, "Garantías y responsabilidades de los protagonistas del cambio verdadero", abarca los artículos 4, 5 y 6 . Señala que podrán afiliarse a Morena los mexicanos mayores de 15 años dispuestos a luchar por un cambio verdadero. No serán admitidos los militantes de otros partidos. Sus afiliados tendrán como derechos registrarse en su lugar de residencia, formar parte de un comité, convencer y concientizar a otros ciudadanos de la importancia de participar en el partido, participar en sus asambleas, integrar y/o nombrar a los representantes en los congresos, consejos $\mathrm{u}$ 
órganos ejecutivos y solicitar que se convoque a un congreso, si así lo decide la tercera parte de sus integrantes. Las obligaciones de los "protagonistas del cambio verdadero" son combatir el régimen de corrupción y privilegios, combatir toda forma de afectación de los procesos electorales y de emisión del voto, difundir las propuestas de Morena y su órgano de difusión denominado "Regeneración", aportar recursos para el mantenimiento de la organización y apoyar la formación de comités de Morena en el territorio nacional y en el exterior.

El capítulo tercero, "Principios democráticos", abarca los artículos 7 a 13. Establece que todos los órganos de dirección de Morena se constituirán buscando garantizar la equidad de la representación, tanto en términos de género como de edad, origen étnico, actividad, condiciones económicas, sociales y de procedencia, así como diversidad y pluralidad. Quien ocupe un cargo de dirección ejecutiva sólo podrá postularse para un cargo del mismo nivel (municipal, distrital, estatal o nacional), después de un periodo de tres años y sólo por una ocasión más. No se permitirá la participación en dos cargos de dirección ejecutiva de manera simultánea. Sus órganos de dirección ejecutiva no incluirán autoridades, funcionarios o integrantes de los poderes Legislativo, Ejecutivo y Judicial. Los consejos estatales y el nacional admitirán la reelección del $30 \%$ de sus miembros de un periodo a otro, por una sola ocasión. Quien aspire a ocupar un cargo de elección deberá separarse del cargo que ocupe en el partido. Si el origen de un cargo de legislador es la vía plurinominal, no podrá postularse por la misma vía a ningún otro cargo de manera consecutiva. En Morena habrá libertad de expresión de puntos de vista divergentes.

Del artículo 14 al 41 bis corre el capítulo cuarto, atinente a la "Estructura organizativa", la cual está constituida por comités de protagonistas de cada barrio, colonia, comunidad o pueblo, o en el exterior. Podrán conformarse por lugar de residencia, afinidades o identidades de género, culturales, sociales o étnicas, así como sectoriales, es decir escuelas, fábricas, ejidos, jóvenes, etcétera. Los comités integrarán una asamblea municipal y serán la autoridad principal de Morena en el ámbito territorial al que corresponda. 
Cada asamblea tendrá un comité municipal y se constituirá en congreso municipal cada tres años.

Morena se organiza con la siguiente estructura: asambleas, consejos y congresos, como órganos constitutivos y de conducción. Como órganos de dirección y ejecución están los comités y coordinaciones. Como órganos electorales están las asambleas y la Comisión Nacional de Elecciones. Como órganos consultivos están los estatales y el nacional. Como órganos jurisdiccionales, las comisiones estatales y la Comisión Nacional de Honestidad y Justicia.

Todos los protagonistas del cambio verdadero deberán estar registrados en el padrón nacional de afiliados. Los comités de protagonistas de Morena deberán tener un mínimo de cinco y un máximo de 60 miembros y reunirse cuando menos cada 15 días. Deberán comprometerse a afiliar protagonistas y construir nuevos comités. Cada comité de protagonistas que se constituya en Morena deberá elegir a dos representantes. La Asamblea Municipal será convocada por el Comité Municipal, para reunirse cada tres meses en forma ordinaria o extraordinaria cuando así se requiera.

La máxima autoridad de Morena será el Congreso Nacional, el cual se reunirá de manera ordinaria cada tres años, al concluir los procesos electorales federales, y de manera extraordinaria, cuando así se requiera. Sus integrantes votarán uno por uno los cargos del Comité Ejecutivo Nacional, el cual durará en su encargo tres años. Estará conformado por 21 personas y conducirá a Morena entre un consejo nacional y otro. Será el encargado de convocar a la realización de los congresos e implementará el plan de acción que resulte de sus acuerdos. Estará conformado por su presidente, quien será su representante nacional, y contará con diversas secretarías como la general, de organización, de finanzas, de comunicación, difusión y propaganda, de educación, formación y capacitación política, de jóvenes, de mujeres, de la diversidad sexual, de indígenas y campesinos, del trabajo, de la producción, de la defensa de los derechos humanos, de estudios y proyecto de nación, para el fortalecimiento de ideales y valores morales, espirituales y cívicos, de arte y cultura, de defensa de los recursos naturales, la soberanía, el medio ambiente y el patrimonio nacional, de bienestar, de combate a la corrupción, 
de cooperativismo, economía solidaria y movimientos civiles y sociales, así como de mexicanos en el exterior y política internacional.

El Comité Ejecutivo Nacional se auxiliará de un Consejo Consultivo Nacional, cuya responsabilidad será elaborar análisis y propuestas para el cumplimiento del plan de acción del Consejo Nacional. Sus miembros fungirán como comisionados electorales al inicio de los procesos electorales.

El Consejo Nacional será la autoridad del partido entre un congreso y otro. Se reunirá de manera regular cada tres meses y tendrá como atribuciones evaluar el desarrollo del partido y hará planteamientos de plan de acción para el periodo siguiente. Otras de sus funciones son conocer las resoluciones sobre conflictos entre órganos de dirección de Morena; elaborar, discutir y aprobar los reglamentos del partido; presentar, discutir y aprobar la plataforma electoral en cada uno de los procesos electorales en que participe; proponer, discutir y aprobar los acuerdos de participación con las agrupaciones políticas nacionales o los frentes o coaliciones con otros partidos políticos en los procesos electorales.

El capítulo quinto, "Participación electoral", va del artículo 42 al 46. En ellos se señala que la plataforma electoral de cada elección en que se participe, deberá aprobarse por el Consejo Nacional y, en dado caso, por los consejos estatales, y estará sustentada en la declaración de principios y programa de Morena. Los candidatos estarán obligados a sostener y difundir la plataforma electoral durante la campaña en la que participen. En los procesos electorales se buscará garantizar la equidad de la representación, en términos de edad, origen étnico, actividad, condiciones económicas, sociales, lugar de residencia y de procedencia, así como la diversidad cultural, lingüística, sexual, social y la pluralidad que caracteriza al pueblo mexicano. No participarán servidores y funcionarios públicos de los poderes Legislativo, Ejecutivo y Judicial, de los tres órdenes de gobierno, a menos que se separen de sus encargos con la anticipación que señala la ley. No se permitirá que los dirigentes promuevan a sus familiares hasta en cuarto grado en línea directa y hasta en segundo por afinidad. Se cancelará el registro del precandidato o candidato que realice conductas que afecten la voluntad de sus miembros y/o de los ciudadanos. 
La selección de candidatos a cargos de representación popular resultará de la utilización armónica de los métodos de elección, insaculación y encuesta que se hayan acordado. Del total de las candidaturas uninominales se destinará hasta el $50 \%$ de las mismas a personalidades externas. Las listas de candidaturas por el principio de representación proporcional incluirán un $33 \%$ de externos que ocuparán la tercera fórmula de cada tres lugares. Las candidaturas externas serán presentadas por la Comisión Nacional de Elecciones al Consejo Nacional del partido para su aprobación final.

Las candidaturas correspondientes a sus propios afiliados y regidas bajo el principio de representación proporcional, se seleccionarán según el método de insaculación. Los afiliados a Morena elegirán en la Asamblea Distrital que les corresponda hasta diez propuestas (cinco hombres y cinco mujeres) por voto universal, directo y secreto, quienes participarán en el proceso de insaculación. La Comisión Nacional de Elecciones, en presencia del Comité Ejecutivo Nacional, la Mesa Directiva del Consejo Nacional y la Comisión Nacional de Honestidad y Justicia, realizará el proceso de insaculación a la vista de los afiliados propuestos por las asambleas distritales. Cada precandidato que resulte insaculado se ubicará secuencialmente en orden de prelación de la lista correspondiente. El primero que salga insaculado ocupará el primer lugar disponible y así sucesivamente hasta completar la lista. Para cumplir lo que marca la ley en materia de equidad de género en la asignación de las candidaturas, se procederá a realizar por separado la insaculación de hombres y mujeres y una vez terminada tal insaculación, se intercalarán los resultados para que por cada dos lugares uno sea para una mujer y otro para un hombre o viceversa.

Las convocatorias de los procesos de selección de candidatos de Morena serán emitidas por el Comité Ejecutivo Nacional según propuesta de la Comisión Nacional de Elecciones. Cada asamblea distrital electoral podrá elegir también por voto universal, directo y secreto, hasta cuatro afiliados para participar en la encuesta que se realizará a fin de determinar las candidaturas uninominales, que corresponderán a quienes se encuentren mejor posicionados. Cada asistente a la asamblea podrá votar por una persona. Un año antes 
de la jornada electoral se determinará por el método de insaculación qué distritos serán destinados a candidaturas externas y cuáles serán asignadas para afiliados del partido. En ambos casos, por medio de encuestas se determinará quiénes serán los candidatos.

En los distritos designados para candidaturas de afiliados de Morena donde se realice encuesta, resultará candidato el mejor posicionado. En los distritos destinados a externos, será candidato el que resulte mejor posicionado en una encuesta en la que participarán cuatro personalidades seleccionadas por la Comisión Nacional de Elecciones. Sin embargo, a juicio de esta comisión y por solicitud expresa del aspirante, en los distritos seleccionados para candidatos externos podrán participar afiliados a Morena, y entre los destinados para afiliados del partido podrán participar externos, cuando la propia comisión presuma que éstos se encuentran mejor posicionados y cuya inclusión en este distrito potenciará adecuadamente la estrategia territorial del partido. En estos supuestos, el candidato será aquel que tenga el mejor posicionamiento, sin importar si es externo en un distrito asignado para un candidato afiliado o afiliado del partido en un distrito destinado para candidato externo.

La selección de candidatos de Morena para presidente municipal, gobernador o presidente de la República se regirá por las mismas bases utilizadas para seleccionar candidatos a diputados por el principio de representación uninominal, mediante las respectivas asambleas electorales municipales, estatales y la nacional, para elegir las propuestas, entre las cuales se decidirá por encuesta al candidato. Las instancias para definir las precandidaturas de Morena en los diversos procesos electorales son: Asamblea Municipal o Delegacional Electoral, Asamblea Distrital Electoral, Asamblea Estatal Electoral, Asamblea Nacional Electoral y Comisión Nacional de Elecciones. Las asambleas municipales electorales y las asambleas distritales electorales estarán abiertas a la participación de todos los afiliados en tales demarcaciones. Las asambleas estatales y la Asamblea Nacional se compondrán por delegados electos en las asambleas municipales y distritales, respectivamente.

El Comité Ejecutivo Nacional designará la Comisión Nacional de Elecciones de entre los miembros del Consejo Consultivo de 
Morena, tres meses antes del inicio de cualquier proceso electoral, siendo con un mínimo de tres y con un máximo de 15 integrantes.

Las competencias de la Comisión Nacional de Elecciones serán: proponer al Comité Ejecutivo Nacional las convocatorias para la realización de los procesos electorales internos, recibir las solicitudes de participación de los interesados y verificar que cubran los requisitos, valorar y calificar los perfiles de los aspirantes y organizar los procesos de selección de precandidaturas, validar y calificar los resultados electorales internos, participar en los procesos de insaculación para elegir candidatos y presentar al consejo nacional las candidaturas de cada género para su aprobación final.

Lo atinente a las comisiones de honestidad y justicia se trata en los artículos 47 a 66 y conforma el capítulo sexto. En él, se señala que es responsabilidad de Morena admitir y conservar en su organización a personas que gocen de buena fama pública. En todas las entidades federativas, estas comisiones serán autónomas y tendrán competencia para resolver las controversias que surjan entre los órganos del partido y sus miembros.

Las facultades de las comisiones de honestidad y justicia son determinar las sanciones a los protagonistas y dirigentes de Morena por infraccionar el estatuto y los reglamentos. Serán autónomas y tendrán competencia para salvaguardar los derechos fundamentales de todos los miembros del partido.

Las faltas con que podrán sancionar las comisiones de honestidad y justicia a sus afiliados serán las referentes a la comisión de actos de corrupción y a la falta de probidad en el ejercicio de su encargo partidista o público, a transgredir las normas y reglamentos de Morena, a incumplir las obligaciones previstas en sus documentos básicos, no cumplir las responsabilidades partidarias, dañar el patrimonio del partido e ingresar o aceptar ser postulado como candidato de otro partido. Las infracciones a la normatividad de Morena serán sancionadas con amonestación privada, amonestación pública, suspensión de derechos partidarios, cancelación del registro en el padrón nacional de afiliados, destitución del cargo en los órganos de dirección y representación, inhabilitación para participar en los órganos de dirección y representación o para ser registrado como candidato para puestos de elección popular, impedimento 
para ser postulado como candidato externo, la negativa o cancelación de su registro como precandidato o candidato, la obligación de resarcir el daño patrimonial ocasionado, así como multas que no podrán exceder de los treinta días de salario mínimo y en caso de reincidencia las multas se duplicarán.

En contra de las resoluciones de las comisiones de honestidad y justicia de las entidades federativas, podrá imponerse un recurso de apelación ante la comisión nacional.

En el capítulo séptimo se trata lo referente a las finanzas de Morena, del artículo 67 al 70. Se establece que el partido se sostendrá de las aportaciones de sus propios integrantes quienes, salvo por situaciones de desempleo o pobreza extrema, contribuirán con el equivalente a un peso diario a su comité de protagonistas. En el caso de legisladores o representantes populares electos por Morena, éstos deberán aportar al partido el equivalente al $50 \%$ de sus percepciones totales (salario, aguinaldo, bonos, prestaciones).

Los recursos que el partido reciba como prerrogativas deberán ser utilizadas exclusivamente en apoyo a la realización del programa y plan de acción de Morena. La Secretaría de Finanzas del Comité Ejecutivo Nacional es el órgano responsable de la administración del patrimonio de Morena y del manejo de sus recursos financieros.

Quien resulte electo candidato externo de Morena para un puesto de representación deberá aportar al partido el equivalente al $50 \%$ de sus percepciones totales durante el tiempo que dure su encargo. La aportación que reciba cualquier dirigente de Morena no se considerará salario ni incluirá prestaciones individuales. Tal aportación no podrá exceder en ningún caso de treinta salarios mínimos.

En el capítulo octavo, "De la reforma a los documentos básicos", en el artículo 71, se señala que la modificación de éstos requerirá de la aprobación de un Congreso Nacional.

En el tercero de los artículos transitorios se establece que los integrantes de los órganos del partido que fueron electos antes del registro de Morena como partido político, durarán en su encargo un periodo de tres años computados a partir de noviembre de 2012, cuando fueron electos. 
EL PROCEDER POLÍTICO DEL PARTIDO Movimiento DE REgENERACIÓN NACIONAL

El domingo 26 de enero de 2014 se realizó en la ciudad de México la Asamblea Nacional Constitutiva de Morena, último requisito que debía cumplir en busca de su registro como partido político nacional, luego de realizar treinta asambleas estatales con un quorum mínimo de tres mil afiliados cada una.

En este encuentro se aprobaron la declaración de principios, el programa y los estatutos de Morena, mismos que fueron entregados posteriormente a la autoridad electoral, junto con la solicitud formal de registro y las boletas de afiliación con que contaba la organización.

Aunque la ley electoral exige la realización de veinte asambleas estatales, con una afiliación mínima de tres mil personas, Morena superó estos requisitos, ya que hasta ese momento se habían realizado asambleas en treinta entidades. Sólo en Sonora y en Baja California Sur no se había logrado contar con el número mínimo de afiliados.

Según datos de las asambleas estatales realizadas por Morena, las cuales fueron verificadas por la autoridad electoral, el requisito de afiliados se cubrió en Oaxaca con 6 mil 691 personas, Puebla con 4 mil 90, Tlaxcala con 3 mil 312, Veracruz con 5 mil 225, Baja California con 3 mil 177, Chiapas con 3 mil 458, Hidalgo con 6 mil 114, Tabasco con 5 mil 802, Guerrero con 3 mil 119, Morelos con 4 mil 20, Zacatecas con 4 mil 816, Chihuahua con 3 mil 176, Jalisco con 4 mil 202, Tamaulipas con 3 mil 500, Michoacán con 3 mil 552, Estado de México con 7 mil 979, Distrito Federal con 11 mil 169, Campeche con 3 mil 311, Quintana Roo con 3 mil 88, Guanajuato con 4 mil 211, San Luis Potosí con 3 mil 460, Durango con 3 mil 600, Yucatán con 3 mil 18, Querétaro con 3 mil 357, Sinaloa con 3 mil 624, Coahuila con 3 mil 729, Aguascalientes con 3 mil 106 y Colima con 3 mil 68. Cabe señalar que estos datos son sólo del día de la realización de cada asamblea estatal y que posteriormente se fueron dando más afiliaciones. Es por ello que hasta el día de la realización de su Asamblea 
Nacional Constitutiva, Morena decía contar con casi medio millón de afiliados. ${ }^{11}$

Una vez aprobados los documentos básicos, López Obrador señaló que las actividades de esta organización no serían exclusivamente como partido político, sino que mantendría su característica de movimiento social, siendo solidario y estando en contacto con otros movimientos sociales, por lo que, vuelto partido, Morena sería un espacio abierto para quienes tuvieran disposición de transformar el país y en el que tendrán cabida indígenas, campesinos, obreros, profesionistas, jóvenes, mujeres, adultos mayores, comerciantes, productores del campo y empresarios. Como partido político, además de participar por primera vez en las elecciones de 2015, buscará derogar todas las reformas aprobadas durante el gobierno de Peña Nieto, particularmente la energética. ${ }^{12}$

Morena logró su registro como partido político nacional cuando el Instituto Nacional Electoral (INE, antes Instituto Federal Electoral) aprobó su inscripción en sesión extraordinaria realizada el 9 de julio de 2014. Cubrió los requisitos legales al enlistar 496 mil 729 militantes, con lo cual superó el requisito del $0.26 \%$ del padrón electoral federal, que era de 219 mil 608, haber realizado treinta asambleas estatales legales, haber conformado treinta y dos comités estatales, dos mil municipales y miles de comités de base, así como trescientas coordinaciones distritales, un Consejo Nacional, treinta y dos consejos estatales y comités ejecutivos en los mismos niveles, con lo que tiene presencia nacional.

A partir de su registro oficial, comenzó a tener derecho a prerrogativas y espacios en radio y televisión luego del 1 de agosto de ese año. Para conservar su membrecía tendría que lograr (y lo logró) más del 3\% de la votación total en los comicios federales de 2015. No obstante haber obtenido su registro, Morena tuvo que hacer cambios a sus documentos básicos por observación del INE, ya que, según el juicio de la autoridad electoral, algunas cláusulas

${ }^{11}$ Juan Flores y Raymundo León, "Hot, asamblea nacional de Morena para constituirse como partido", La Jornada, 26 de enero de 2014, p. 7.

12 Enrique Méndez y Alma E. Muñoz, "Ya como partido, Morena derogará todas las reformas de Peña: AMLo", La Jornada, 27 de enero de 2014, p. 7. 
relacionadas con la integración de sus órganos no se eran consideradas democráticas.

Según lo previsto en la Ley General de Instituciones y Procedimientos Electorales y en la Ley de Partidos Políticos, Morena tuvo que ajustar sus estatutos y demás reglamentaciones internas en lo referente a la integración definitiva de sus órganos directivos nacionales y estatales, además de la acreditación de sus representantes ante los consejos del InE. Entre sus principales adecuaciones tuvo que señalar los procedimientos democráticos para la integración y renovación de comités de protagonistas del cambio verdadero y de coordinadores distritales, establecer el método para la constitución de comités municipales y las normas para la postulación democrática de sus candidatos. ${ }^{13}$ El 15 de septiembre de 2014 se realizó el Primer Congreso Nacional Extraordinario de Morena, en el cual se aprobaron los cambios sugeridos por el INE.

En un proceso novedoso, pero apegado a sus estatutos, Morena eligió por medio de un sorteo (insaculación, según sus estatutos) entre sus militantes, a dos terceras partes de sus candidatos plurinominales a diputados para la elección de 2015. La otra tercera parte fueron candidatos externos provenientes de la academia, activistas, profesionistas, gente vinculada con el deporte o de amplia trayectoria política, propuestos por la Comisión Nacional de Elecciones. En el sorteo participaron como aspirantes cerca de tres mil afiliados, los cuales fueron designados en asambleas distritales previas. ${ }^{14}$ Con esto, como dijo López Obrador, fue la suerte, y no el dedazo, la que determinó las candidaturas a diputaciones federales, tal y como se hacía en la antigua Grecia para elegir a los magistrados de entre la totalidad de los ciudadanos. ${ }^{15}$

${ }^{13}$ Georgina Saldierna, "Obtiene Morena registro como partido; lo aprueba el Consejo General del INE”, La Jornada, 10 de julio de 2014, p. 12.

${ }^{14}$ A. E. Muñoz y José Antonio Román, "Morena elige por sorteo a dos terceras partes de candidatos plurinominales a diputados", La Jornada, 24 de febrero de 2015 .

${ }^{15}$ José Antonio Aguilar Rivera, "La tómbola caciquil”, Nexos, núm. 448, abril de 2015, p. 18. Una crítica a esta forma de selección interna de candidatos puede verse en Claudio López-Guerra, "Morena y el falso sorteo", Nexos, núm. 448, abril de 2015, pp. 22-23. 
En las elecciones locales de 2015, en el Distrito Federal se logró cambiar el mapa político, ya que el PRD dejó de tener la gran mayoría de las delegaciones y de los puestos en la Asamblea Legislativa del Distrito Federal (ALDF), la cual tenía prácticamente desde 1997. Morena debutó como partido en el Distrito Federal, ganando en cinco delegaciones: Azcapotzalco, Cuauhtémoc, Tláhuac, Tlalpan y Xochimilco. Ya con el reparto de las diputaciones plurinominales en esta entidad, Morena se quedó con veinte de los sesenta y seis espacios en la ALDF, convirtiéndose en la primera minoría.

En el ámbito nacional, para la elección de diputados federales, Morena quedó en quinto lugar con $8.39 \%$ de los votos y treinta y cinco diputaciones (catorce de mayoría y veintiún de representación proporcional). Con estos resultados, Morena alcanzó su registro y se constituye como el nuevo polo de la izquierda. Para el trienio 2015-2018, cuenta con un significativo grupo parlamentario en el ámbito federal y en las elecciones de 2015 alcanzó el primer lugar en el Distrito Federal, el segundo en Quintana Roo, y en diecisiete entidades se coloca por encima del PRD. ${ }^{16}$

En el primer balance del proceso electoral de 2015 que hizo el Consejo Nacional de Morena, se acordó seguir trabajando unidos para llevar a López Obrador como su candidato a la presidencia en 2018. Otros acuerdos fueron destinar la mitad de las prerrogativas del partido, así como una parte de las subvenciones y dietas de sus legisladores, para constituir un fondo que se destinará a la educación en los lugares gobernados por Morena, con objeto de aumentar la matrícula y reducir el número de estudiantes rechazados. Se fijó la agenda legislativa en la que se incluye el rechazo a la privatización del agua, abolir las reformas estructurales del gobierno de Enrique Peña Nieto, particularmente la energética e impulsar una política de austeridad gubernamental. Se avaló que los grupos parlamentarios de Morena ejerzan un código de ética en el que se comprometan a renunciar a prebendas como bonos y viajes al extranjero bajo el principio de austeridad. Se aprobó que, por

16 Alejandro Encinas Rodríguez, "Saldo electoral", Proceso, núm. 2017, 1 de julio de 2015, p. 42. 
convocatoria del Comité Ejecutivo Nacional, los diputados federales y asambleístas elegirían a sus coordinadores. ${ }^{17}$

Para la LXIII legislatura (2015-2018), Rocío Nahle García fue electa como coordinadora en la Cámara de Diputados y como vicecoordinador a Virgilio Caballero, por decisión de todos los legisladores de Morena, sin que el Comité Ejecutivo Nacional interviniera en dichos nombramientos, ${ }^{18}$ respetando la autoridad e independencia de cada instancia.

Concluido el proceso electoral de 2015, el Consejo Nacional de Morena aprobó el mecanismo de selección para la próxima dirigencia que sustituiría a la encabezada por Martí Batres (quien concluyó su encargo en septiembre y pasó a ocupar la presidencia de Morena en el Distrito Federal al ganar la elección correspondiente), así como a los comités estatales, y definió emitir la convocatoria respectiva el 20 de agosto. ${ }^{19}$ Durante dos meses Bertha Elena Luján, quien fuera secretaria general de Morena, ocupó la presidencia nacional en forma interina, mientras se realizaba la nueva elección.

Andrés Manuel López Obrador se convirtió por unanimidad en presidente nacional de Morena para el periodo 2015-2018, con la aprobación de los casi mil 600 delegados que asistieron al Segundo Congreso Nacional de Morena, realizado el 20 y 21 de noviembre de 2015. Gente cercana a él ocupó las otras veinte carteras del Comité Ejecutivo Nacional. Por ejemplo, Yeidckol Polevnsky se convirtió en secretaria general; Alejandro Esquer, en secretario de finanzas; César Yáñez obtuvo el cargo de comunicación, difusión y propaganda; Gabriel García, el de organización; Mauricio Hernández, el de educación, formación y capacitación política;

${ }^{17}$ E. Méndez, "Ganar la presidencia en 2018, siguiente objetivo de Morena, señala López Obrador”, La Jornada, 15 de junio de 2015, p. 7.

${ }^{18}$ Mayolo López, "Toma Morena protesta a nueva coordinadora”, Reforma, 24 de julio de 2015, p. 8.

${ }^{19}$ E. Méndez, "Morena inicia proceso para nombrar líder que afrontará elecciones de 2018”, La Jornada, 10 de agosto de 2015, p. 14. Martí Batres resultó electo presidente de Morena en el Distrito Federal para el periodo 2015-2018, al obtener 132 votos a favor, frente a su competidor Alejandro Rojas Díaz-Durán. Como secretario general, fue electo Alfonso Ramírez Cuéllar, y como secretaria de organización, Donají Alba. 
Héctor Vasconcelos, el de la secretaría de mexicanos en el exterior y la política internacional; Hugo Alberto Martínez, el de defensa de los recursos, la soberanía, el medio ambiente y el patrimonio nacional; Carlos Alberto Figueroa, el de defensa de los derechos humanos; José Magdaleno Rosales, el de estudios y proyectos de la nación; Martín Sandoval, el de fortalecimiento de ideas y valores espirituales y cívicos; Isaac Martínez dedicaría su atención a los jóvenes; Karen Arriaga, a las mujeres; Marco Antonio Villanueva, a la diversidad sexual; Armando Contreras, a indígenas y campesinos; y Carlos Alberto Evangelista, al combate de la corrupción. También se renovó el Consejo Nacional, con el nombramiento de 200 integrantes. Bertha Elena Luján, la ex presidente interina en sustitución de Martí Batres, fue nombrada presidente del Consejo Nacional, cargo que dejó López Obrador, ${ }^{20}$ con lo que prácticamente se dio un enroque.

Como resultado de este Congreso Nacional y de la elección de López Obrador como dirigente nacional de Morena, se formaliza su liderazgo absoluto y se adelanta su candidatura a la Presidencia de la República para 2018. El control de López Obrador y sus seguidores sobre Morena atrajo las críticas de aquellos que, ajenos al partido, veían censurables la figura de la candidatura única, la elección por aclamación y no por votación en urnas, el enroque de presidencias del Consejo Nacional al Comité Ejecutivo Nacional, y viceversa, y la lista de ocupantes, sin equidad de género, a las diversas secretarías por parte de los allegados a Andrés Manuel.

Después de tomar protesta como presidente nacional de Morena, López Obrador dio a conocer la estrategia que el partido implementará para contender en las elecciones de 2018 por la Presidencia de la República y por la mayoría del Congreso de la Unión. Para ello, propuso nombrar trescientos dirigentes, uno por distrito electoral, para ocuparse de tiempo completo de la integración de comités de base o de protagonistas del cambio verdadero, que realicen tareas de afiliación, de promoción y de defensa del voto. La meta era que en un año se tuvieran comités en todas

${ }^{20}$ A. E. Muñoz, "Andrés Manuel López Obrador, presidente nacional de Morena”, La Jornada, 21 de noviembre de 2015, p 12. 
las secciones electorales del país. También se imprimirá nuevamente el periódico Regeneración, como órgano de difusión de Morena. Se convocará a un congreso nacional extraordinario el 20 de noviembre de 2016, para evaluar el avance de la estrategia y el proyecto alternativo de nación para 2018, además de revisar los estatutos del partido, con el propósito de lograr la equidad de género en la dirección nacional. ${ }^{21}$

López Obrador ha creado su propio partido, que dirige formalmente desde noviembre de 2015. Ya no tiene que lidiar con los intereses, grupos y dinámicas propios de toda organización política. Antaño usufructuó al PRD, al PT y a Convergencia / Movimiento Ciudadano, pero también éstos se sirvieron con creces de él, no sólo por las prerrogativas obtenidas de las favorables votaciones que obtenía. Ahora, Morena es su partido y recoge su programa y su proyecto. Cuenta con una estructura partidista totalmente afín a su proyecto personal. ${ }^{22}$

Convertido en el líder real y formal de Morena, López Obrador tiene todas las condiciones a su favor para convertirse por tercera ocasión en candidato presidencial, cuando llegue el año de 2018. Mantiene su imagen como la figura más fuerte de la oposición y con amplio reconocimiento por parte de la población en general. Al menos en Morena, el partido que formó y que es la culminación del movimiento lopezobradorista iniciado en 2006, no tendrá a nadie que compita contra él para esa candidatura.

Desde nuestra perspectiva, López Obrador avanza con fuerza hacia 2018, principalmente porque ahora puede moverse desde una posición estratégica que es la Dirigencia Nacional de Morena. Su experiencia en la política nacional es fundamental, pues lleva una década como candidato presidencial -aunque no todo el tiempo de manera oficial-y, para 2018, prácticamente contará trece años en campaña. Conoce el pulso completo de México, ha recorrido el país varias veces y al parecer

${ }^{21}$ A. E. Muñoz, "Delinea López Obrador la estrategia de Morena para ganar la presidencia en 2018”, La Jornada, 22 de noviembre de 2015, p. 6.

22 Federico Berrueto, “Amlo en el espejo de Podemos", Milenio, 22 de noviembre de 2015, p. 3. 
en esta ocasión llega con una posición un poco más moderada y de mayor aceptación. ${ }^{23}$

Con la realización de su Segundo Congreso Nacional, el 20 de noviembre de 2015, terminó la primera etapa de la construcción de Morena. En sus primeros años, Morena logró posicionarse frente a la sociedad y hacerse con una identidad propia.

En 2013, combinó la difícil tarea de convocar a la movilización en defensa del petróleo, a la vez que realizó las asambleas que marca la ley para la obtención de su registro como partido político.

En 2014, realizó su Asamblea Nacional Constitutiva, concretó los trámites para su registro, lo obtuvo e hizo una intensa campaña de recolección de firmas para demandar una consulta vinculatoria sobre el petróleo. Ese mismo año, llevó a cabo su primer Congreso Nacional Extraordinario para reformar sus estatutos según los requerimientos de la autoridad electoral.

En 2015, puso en marcha la definición de candidaturas, prácticamente sin conflicto interno y echando a andar un novedoso sistema de selección de candidatos que combina elecciones, sorteos, consensos y designación de ciudadanos externos. En su selección de candidaturas, pudo ponderar la presencia de numerosas personalidades con prestigio social, lo que, aunado a la organización de base y al liderazgo de López Obrador, fueron los cimientos para que Morena lograra resultados satisfactorios en las elecciones federales de 2015, con los cuales logró mantener su registro, se convirtió en la oposición política real en el país y en la primera fuerza electoral en el Distrito Federal. Todo eso se logró por una dirección unificada, sin conflicto interno. 24

\section{Conclusiones}

Es muy común que las dirigencias de los partidos tengan el doble carácter de una apariencia democrática y una realidad oligárquica,

${ }^{23}$ Magali Juárez, "Futuro incierto”, Cambio, núm. 709, del 29 de noviembre al 5 de diciembre de 2015, pp. 13-14.

${ }^{24}$ Martí Batres, "Morena, los primeros años", Milenio, 26 de noviembre de 2015, p. 8 . 
ya que a pesar de que pueden contar con normas internas para regular su funcionamiento democrático, la práctica política los conduce al autoritarismo. Aunque los dirigentes de los partidos se esfuercen por conservar una apariencia democrática, suele ser común que los procedimientos autoritarios y oligárquicos se desarrollen al margen de sus estatutos o incluso en ellos.

La forma de autoridad se modifica en los partidos. En una primera fase, se pasa lentamente de una dirección personal a una dirección institucional y en ocasiones esto puede tender a la oligarquía, además de incidir negativamente en su vida interna y afectar su democracia.

Es de mencionar que aun cuando las elecciones internas sean formalmente democráticas y abiertas a todos los militantes, también puede prevalecer en ellas la manipulación del voto directo mediante mecanismos como el de obstaculizar que los disidentes a la dirigencia puedan ejercer su voto y favorecer que los no opositores puedan ejercerlo sin dificultad, o cuando se sabotean las elecciones y se manipulan los votos, si los resultados son adversos o también cuando no se respeta la secrecía del voto. ${ }^{25}$ Más aún: es muy común que la democracia en los partidos de reciente creación esté limitada por el control de sus líderes fundadores mediante el manejo de sus estructuras (como es el caso de Morena con López Obrador). Esto origina la influencia de tales liderazgos en los procesos de selección de candidatos para puestos de elección y dirigentes partidistas. ${ }^{26}$

Cuando en un partido hay un liderazgo que centraliza las decisiones y los deseos de un grupo bien identificado de dirigentes que se enquista en los cargos prevalecen sobre la mayoría de los militantes, entonces se presenta un proceso de oligarquización. Esto se puede contrarrestar con la aplicación de tendencias

${ }^{25}$ Mauricio Duverger, op. cit., pp. 164-165, 170 y 174-175.

${ }^{26} \mathrm{Al}$ respecto, véase Joaquín Balancán Aguirre y Carlos Guadarrama Cruz, "La democracia interna en los estatutos de los partidos minoritarios de México", en Gabriel Corona Armenta (coord.), Democracia interna y tendencias oligárquicas de los partidos políticos en México: Partido Verde Ecologista, Partido del Trabajo, Movimiento Ciudadano y Nueva Alianza, México, Facultad de Estudios Superiores AcatlánUNAM-Gernika, 2014, p. 570. 
democratizadoras en un partido si, hay una distribución de responsabilidades entre sus militantes; si se discuten las decisiones y se aprueban por mayoría; si se fomenta la movilidad de los dirigentes; si se garantizan todos los derechos de los militantes; si se fortalece la organización y los procedimientos internos; si se reglamentan las corrientes o fracciones para permitir el pluralismo en su interior; si se aseguran controles internos y externos a la propia organización política; si la militancia elige mediante votación abierta y en asambleas a sus dirigentes y candidatos para puestos de elección popular, y si se da la prohibición de ocupar dos o más cargos partidistas a la vez. Es muy común que todos los partidos políticos se proclamen internamente como democráticos, aunque en realidad no lo sean, presentando frecuentemente el doble carácter de una apariencia democrática y de una realidad oligárquica. ${ }^{27}$

A partir del caso de Morena, en este trabajo se buscó resaltar la necesidad de estudiar la democracia interna y las tendencias oligárquicas que se presentan en los partidos políticos, porque son de gran importancia para conocer sus prácticas, arreglos y valores inherentes a su conducta política interna, sus liderazgos (reales y formales, institucionales y personales), los procedimientos de selección de dirigentes y candidatos para puestos de elección popular, la relación de las bases con su dirigencia, así como la participación de la militancia en los asuntos del partido y en la toma de decisiones. Para ello, se analizaron los documentos básicos de Morena, la práctica política real del partido para conocer y evaluar la forma en que se da la selección de sus candidatos para puestos de elección y de sus cuadros dirigentes, para conocer cuán democrático es internamente y sus tendencias oligárquicas.

Según sus estatutos, formalmente en el partido se cumple el principio de democracia interna, porque la militancia participa en la selección para cargos de elección popular y en la selección de dirigentes partidistas. Pero así como en Morena se cumplen estos

27 G. Corona Armenta, "Tendencias oligárquicas y democratizadoras del PRI, PAN y PRD durante las elecciones de sus dirigentes nacionales (México 1988-2012)”, en F. Casanova Álvarez y G. Corona Armenta (coords.), op. cit., pp. 311-326. 
requisitos de democracia interna, también presenta un proceso de oligarquización, toda vez que los ocupantes de los cargos partidistas de dirección se convierten necesariamente en un equipo compacto, independientemente de su forma de elección. Los liderazgos reales y formales se convierten en cuerpos burocráticos que centralizan la autoridad y la toma de decisiones, teniendo la habilidad de evitar la disidencia y la oposición interna, ofreciendo incentivos, negociando con ésta y/o cooptándola, para que desaparezca. No hay facciones ni corrientes o grupos en su interior que vulneren la soberanía de la organización y el poder se encuentra centralizado en la figura carismática de López Obrador.

El enorme peso de López Obrador y la dirigencia del partido sobre las bases hace que en Morena las elecciones internas (para directivos del partido y candidatos para puestos de elección popular) y las distintas votaciones que se realizan internamente, como la aprobación de sus documentos básicos, se acepten prácticamente por unanimidad, lo que pareciera frenar toda posibilidad de discusión y análisis.

En Morena se cumple lo referente a que todos los partidos políticos, en su etapa inicial, giran en torno a las ideas, propuestas y decisiones de su líder fundador, es decir Andrés Manuel López Obrador. Lo deseable sería que en el corto plazo se fuera consolidando su institucionalización, en la cual el partido sea cohesionado por su programa, sus principios y sus estatutos, y no sólo por un liderazgo personalizado y carismático.

Morena obtuvo su registro como un partido político con una base social amplia y una verdadera postura opositora a los poderes dominantes. Su fuerza radica en la personalidad y el liderazgo de López Obrador y en miles de ciudadanos que creen necesario organizar su propio partido para intentar un cambio de fondo en México. En la dependencia extrema de su dirigente máximo radica uno de los principales problemas a los que se enfrentará para lograr su institucionalización. 


\section{BibliogRAFíA}

Aguilar Rivera, José Antonio, "La tómbola caciquil”, Nexos, México, núm. 448, 1 de abril de 2015.

Balancán Aguirre, Joaquín y Carlos Guadarrama Cruz, "La democracia interna en los estatutos de los partidos minoritarios de México”, en Gabriel Corona Armenta (coord.), Democracia interna y tendencias oligárquicas de los partidos políticos en México: Partido Verde Ecologista, Partido del Trabajo, Movimiento Ciudadano y Nueva Alianza, México, Facultad de Estudios Superiores Acatlán-Universidad Nacional Autónoma de México-Gernika, 2014.

Batres, Martí, "Morena, los primeros años", Milenio, 26 de noviembre de 2015.

Berrueto, Federico, “AmLo en el espejo de Podemos”, Milenio, 22 de noviembre de 2015.

Bolívar Meza, Rosendo, "El lopezobradorismo: la construcción de un movimiento social y político”, El Cotidiano, México, núm. 178, marzoabril de 2013, pp. 81-92.

, "La oligarquización del Partido de la Revolución Democrática bajo la dirigencia de Nueva Izquierda”, en Francisco Casanova Álvarez y Gabriel Corona Armenta (coords.), Democracia interna y tendencias oligárquicas de los partidos políticos en México: PAN, PRI y PRD, México, Facultad de Estudios Superiores Acatlán-Universidad Nacional Autónoma de México-Gernika, 2013.

— , "Los frentes político-electorales de izquierda en México (20062012), Estudios Políticos, núm. 28, enero-abril de 2013, pp. 51-79.

, "Morena: el partido del lopezobradorismo", Polis, vol. 10, núm. 2, 2014, pp. 71-103.

Cárdenas Gracia, Jaime, Crisis de legitimidad y democracia interna de los partidos políticos, México, Fondo de Cultura Económica, 1992.

Casanova Álvarez, Francisco y Víctor Rosales García, “Oligarquía y tendencias oligárquicas de los partidos políticos mexicanos”, en Francisco Casanova Álvarez y Gabriel Corona Armenta (coords.), Democracia interna y tendencias oligárquicas de los partidos políticos en México: PAN, PRI y PRD, México, Facultad de Estudios Superiores Acatlán-Universidad Nacional Autónoma de México-Gernika, 2013. 
Corona Armenta, Gabriel, "Tendencias oligárquicas y democratizadoras del PRI, PAN y PRD durante las elecciones de sus dirigentes nacionales (México 1988-2012)", en Francisco Casanova Álvarez y Gabriel Corona Armenta (coords.), Democracia interna y tendencias oligárquicas de los partidos políticos en México: PAN, PRI y PRD, México, Facultad de Estudios Superiores Acatlán-Universidad Nacional Autónoma de México-Gernika, 2013.

Duverger, Mauricio, Los partidos políticos, México, Fondo de Cultura Económica, 1984.

Encinas Rodríguez, Alejandro, "Saldo electoral", Proceso, núm. 2017, 1 de julio de 2015, en http://hemeroteca.proceso.com.mx/?p=409303

Espejel Espinoza, Alberto, "El estado de la cuestión de la democracia interna”, en Francisco Casanova Álvarez y Gabriel Corona Armenta (coords.), Democracia interna y tendencias oligárquicas de los partidos politicos en México: PAN, PRI y PRD, México, Facultad de Estudios Superiores Acatlán-Universidad Nacional Autónoma de México-Gernika, 2013.

Flores, Juan y Raymundo León, "Hot, asamblea nacional de Morena para constituirse como partido", La Jornada, 26 de enero de 2014.

Gallo, Adriana, "La democracia interna en el ámbito partidario. Un estudio comparado en partidos latinoamericanos", Reflexión Política, vol. 7, núm. 14, 2005, pp. 26-39.

Juárez, Magali, "Futuro incierto", Cambio, México, núm. 709, del 29 de noviembre al 5 de diciembre de 2015.

Linz, Juan J., Michels y su contribución a la sociología, México, Fondo de Cultura Económica, 1998.

López, Mayolo, "Toma Morena protesta a nueva coordinadora", Reforma, 24 de julio de 2015.

López-Guerra, Claudio, "Morena y el falso sorteo", Nexos, núm. 448, abril de 2015.

Méndez, Enrique y Alma E. Muñoz, "Ya como partido, Morena derogará todas las reformas de Peña: AmLo”, La Jornada, 27 de enero de 2014.

_- "Ganar la presidencia en 2018, siguiente objetivo de Morena, señala López Obrador”, La Jornada, 15 de junio de 2015.

_- "Morena inicia proceso para nombrar líder que afrontará elecciones de 2018", La Jornada, 10 de agosto de 2015.

Michels, Robert, Teoría y sociología críticas de los partidos políticos, Barcelona, Anagrama, 1980. 
Muñoz, Alma E. y José Antonio Román, "Morena elige por sorteo a dos terceras partes de candidatos plurinominales a diputados", La Jornada, 24 de febrero de 2015.

— , "Andrés Manuel López Obrador, presidente nacional de Morena”, La Jornada, 21 de noviembre de 2015.

— , "Delinea López Obrador la estrategia de Morena para ganar la presidencia en 2018”, La Jornada, 22 de noviembre de 2015.

Panebianco, Ángelo, Modelos de partido, México, Alianza Universidad, 1990.

Saldierna, Georgina, "Obtiene Morena registro como partido; lo aprueba el Consejo General del InE”, La Jornada, 10 de julio de 2014, p. 12.

Sánchez Rebolledo, Adolfo, "Una izquierda para la mayoría”, Nexos, México, núm. 418, octubre de 2012. 